\title{
Elaboration of testing technique of flat slabs on punching shear strength using finite element modeling
}

\author{
Valery Filatov ${ }^{1, *}$, Zulfat Galyautdinov ${ }^{1}$, and Alexander Suvorov ${ }^{1}$ \\ ${ }^{1}$ Samara State Technical University, Academy of Civil Engineering and Architecture, \\ Molodogvardeyskaya St., 194, Samara, 443001, Russia
}

\begin{abstract}
The results of researches on finite-element models of stressstrain state of flat reinforced concrete slabs of beamless frame under punching by columns of square and rectangular cross-section are presented. The purpose of the study was to develop a technique for testing samples plates for punching in the presence of bending moments in a column. The results of the study of deflections of reinforced concrete slabs, the distribution of bending moments in the punching zone of the plate under various loading schemes are presented. Variable parameter was the ratio of the sides of the column cross-section. Comparative analysis of studies results on finite element models has made it possible to choose the optimal variant of applying the load to the test samples, depending on the aspect ratio of rectangular section of column. Results of the conducted research will allow simulating the stress-strain state in the punching zone of natural reinforced concrete slabs of monolithic beamless frame during the test of samples.
\end{abstract}

\section{Introduction}

The results of studies of flat plate's resistance to punching are presented in the works of many authors, among which are the works [1-8]. Reliable research results can be obtained only in the presence of the correct method of testing. One of the issues to be addressed in the test procedure is the correct pattern of sample loading. The correct pattern of loading samples involves creating in the sample fields of forces and displacements, which correspond to the maximum extent of the distribution of forces and displacements when loading the operated structure. Note that the floor slabs of the building are loaded, as a rule, uniformly distributed load.

When testing the samples of plates for punching, various loading schemes are implemented. With the central location of the loading area relative to the center of gravity of test plate, only normal force $\mathrm{N}$ is transferred to the plate. When the loading area is located on the edge of sample plate, the normal force $\mathrm{N}$ and the bending moment $\mathrm{M}$ are

\footnotetext{
Corresponding author: vb_filatov@mail.ru
} 
transferred to the plate. Part of the moment acting in the column is taken into account when calculating the plate for punching [9-12].

Numerical investigation on finite element models was performed to determine the correct loading scheme for testing samples under the combined action of normal force $\mathrm{N}$ and bending moment $\mathrm{M}$. It is known that under the action of a uniformly distributed load and concentrated forces on the slab, the character of plate deformation differs [13-15]. In the design of reinforced concrete structures is considered, as a rule, the impact of uniformly distributed loads, while the tests of samples load is applied in the form of concentrated forces. When testing linear structures (beams, columns), this difference is not so significant, or can be compensated by the calculation method, but for plate structures operating in two directions, the influence of the loading scheme may be significant $[16,17]$. Numerical methods are an effective tool and have been successfully used $[18,19]$ to study the stress strain state of reinforced concrete structures.

\section{Materials and Methods}

The numerical study was performed on finite element models developed for three samples in the "LIRA-SAPR 2014"environment. Experimental samples made of heavy concrete were a fragment of monolithic joint of a column of rectangular section with flat plate. Variable parameter was the ratio of the sides of column section $200 \times 200 \mathrm{~mm}(1: 1), 200 \times$ $500 \mathrm{~mm}(1: 2.5)$ and $200 \times 800 \mathrm{~mm}(1: 4)$. Testing of the samples was supposed to be carried out in the test stand by applying a load until the reinforced concrete slab was punched by column.

The task of the numerical investigation was to determine such a scheme for applying concentrated forces on a plate of the test sample, in which the stress state of the plate elements in the zone of punching would be most consistent with the stress state of the plate elements in the zone of punching under the action of a uniformly distributed load.

The finite-element models of test samples were a flat reinforced concrete slab (finite element - "shell") on the edge of which there is a fragment of the column (finite element "rod"). Plate and column connection was modeled by the options "absolutely rigid body" which was set in plate nodes and "absolutely rigid insert" which was set in rods (columns). The dimensions of the "absolutely rigid body" varied and corresponded to the cross section of the column $-200 \times 200 \mathrm{~mm}, 200 \times 500 \mathrm{~mm}$ and $200 \times 800 \mathrm{~mm}$.

Forces resulting from calculations on sample models were compared with forces in the zone of punching the floor slab of a multi-storey building loaded with uniformly distributed load. The finite-element model of multi-storey building was a monolithic girderless floors frame with a grid of columns $6 \times 6$ meters. The height of the floor is 3.3 meters, the cross section of the column was taken $300 \times 300 \mathrm{~mm}, 300 \times 750 \mathrm{~mm}$ and $300 \times 1200 \mathrm{~mm}$, the thickness of the plate- $200 \mathrm{~mm}$. Simulation of the column-plate interface was performed using "absolutely rigid insert" for the rods and "absolutely rigid bodies" for the plate elements. On the floors of the building applied uniformly distributed load. The ratio of forces and displacements in the zone of slab punching by edge column was analyzed with variation of the following parameters: the size of cross section of the column, the thickness of the slab, the modulus of elasticity of concrete, the load on the slab.

At first stage, the stress state of slab of a multi-storey building under the action of uniformly distributed load was investigated. Analysis of forces and displacements in the zone of slab punching by edge column was carried out.

At second stage, the stress state of test sample plate was investigated under the action of concentrated forces on the areas provided for by the design of the test stand. In this case, the position of loading points along the outer face of the plate varied. The position of the loading points on the plate was chosen in such a way that the distribution of forces in the 
punching zone of test sample plate corresponded most closely to the slab stressed state of multi-storey building under the action of a uniformly distributed load.

In addition to distribution of forces in the punching zone of test sample plate, the ratio of the magnitude of bending moment and punching force $\mathrm{M} / \mathrm{N}$ in cross section of the column at plate level was monitored. Position of the loading points on test sample's plate was adopted in such a way that the $\mathrm{M} / \mathrm{N}$ ratio in the first and second stages of the study was as close as possible.

\section{Results}

Fields of bending moments $\mathrm{M}_{\mathrm{x}}$ and $\mathrm{M}_{\mathrm{y}}$ in the test sample's plate and the slab of the multistorey building, obtained by numerical study, are presented on figure 1 (aspect ratio of the column cross-section is $1: 1$ ).

a) $\mathrm{M}_{\mathrm{x}}, \mathrm{kN} \cdot \mathrm{m}$

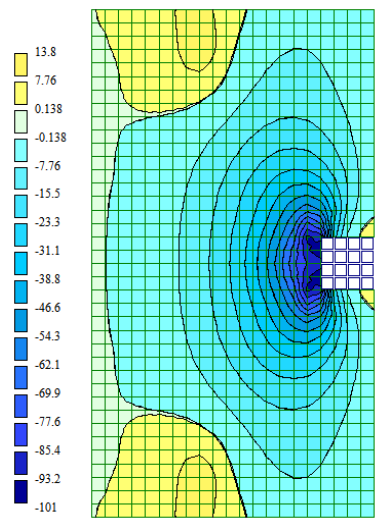

b) $\mathrm{M}_{\mathrm{x}}, \mathrm{kN} \cdot \mathrm{m}$

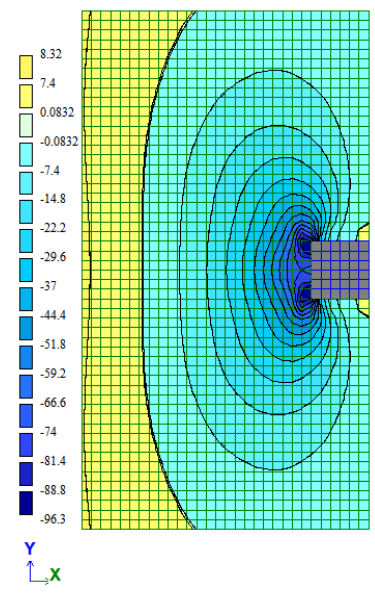

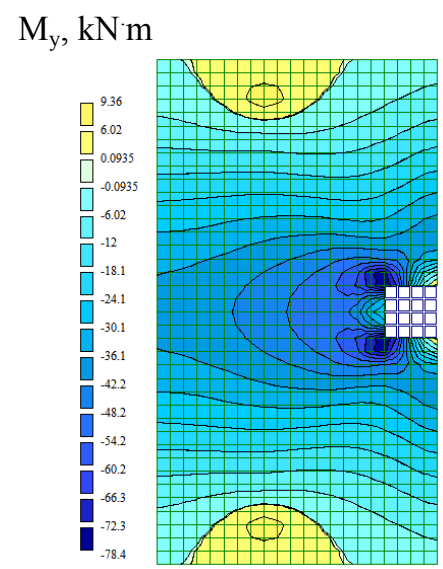

$\mathrm{M}_{\mathrm{y}}, \mathrm{kN} \cdot \mathrm{m}$

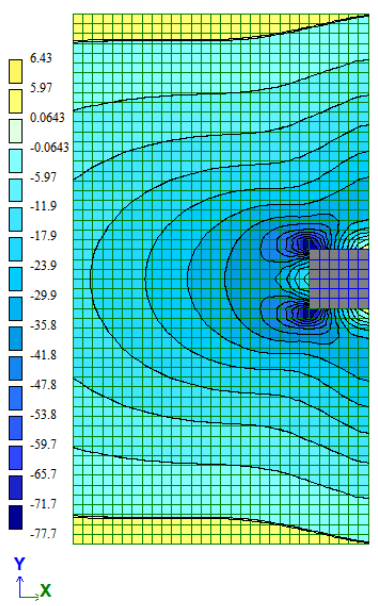

Fig. 1. Fields of bending moments $M_{x}$ and $M_{y}$ in the plate under concentrated forces (a) and uniformly distributed loading (b).

Distributions of bending moments $\mathrm{M}_{\mathrm{x}}$ and $\mathrm{M}_{\mathrm{y}}$ in longitudinal and transverse directions for the test sample's plate and for slab floor of multi-storey building (for ratio of the sides of column's section 1:1, 1:2.5 and 1:4) are shown on figure 2 .

The results of study on finite element model of multi-storey building showed that the ratio of bending moment and punching force $\mathrm{M} / \mathrm{N}$ varies in the range of $0.25-0.35$. In the 
experiments of authors [20-23], M / N ratio was assumed to be 0.3 at the punching tests, which corresponds to average value of investigated range.
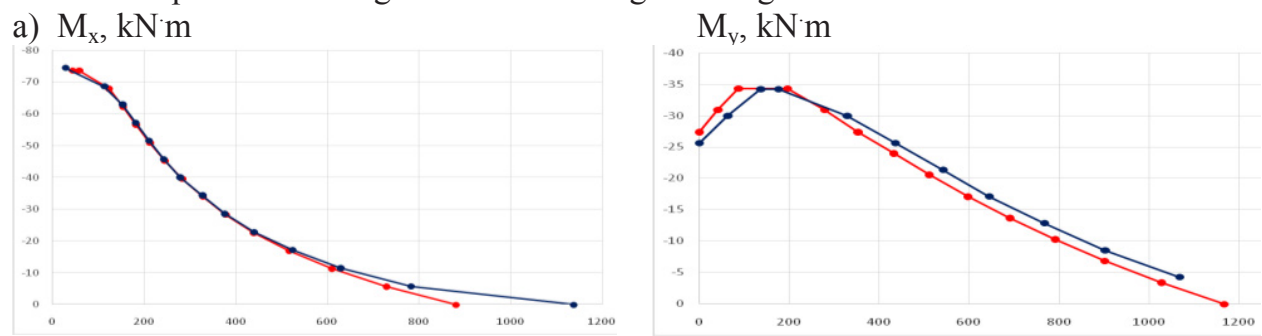

b) $\mathrm{M}_{\mathrm{x}}, \mathrm{kN} \cdot \mathrm{m}$

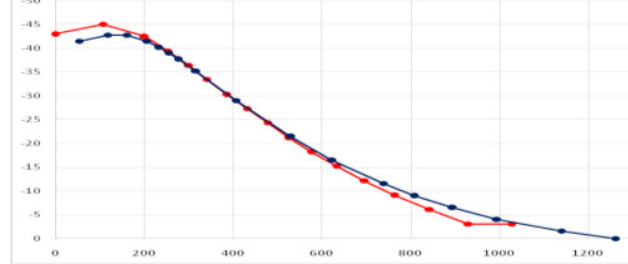

$\mathrm{M}_{\mathrm{y}}, \mathrm{kN} \cdot \mathrm{m}$

c) $\mathrm{M}_{\mathrm{x}}, \mathrm{kN} \cdot \mathrm{m}$
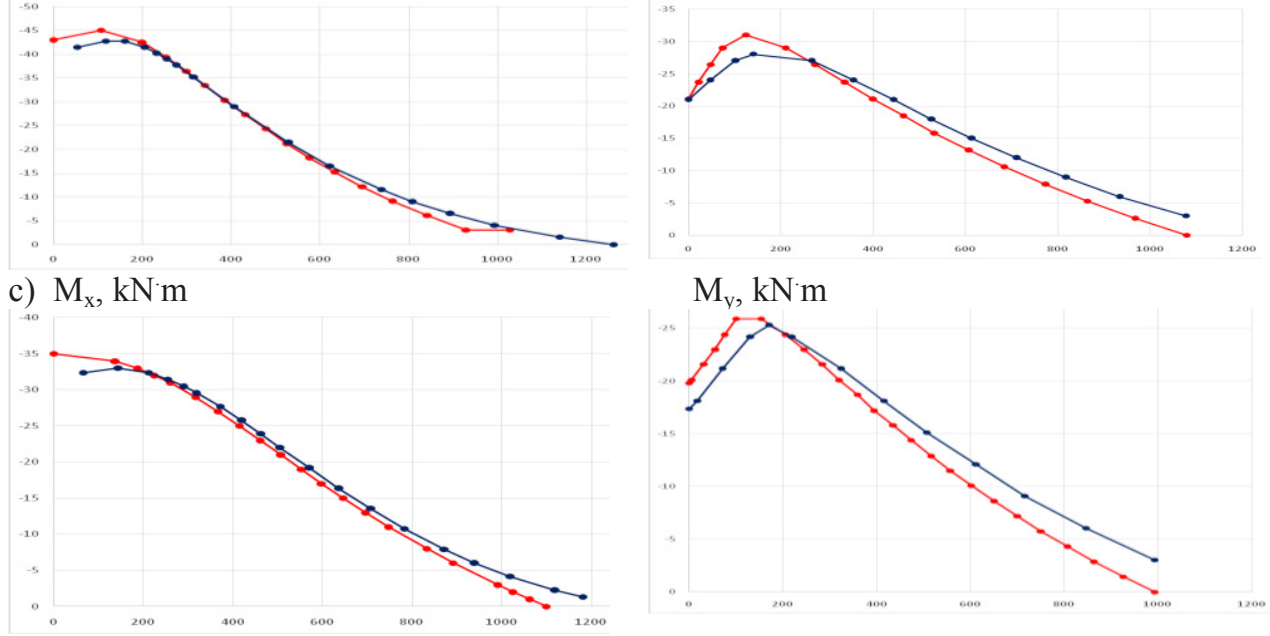

Fig. 2. Distribution of bending moments $M_{x}$ and $M_{y}$ in the plate for ratio of the sides of column's section 1:1 (a), 1:2.5 (b), 1:4 (c). Red line - building's slab; blue line - test sample.

For the test sample models, concentrated forces were applied to the plate in such a way that $\mathrm{M} / \mathrm{N}$ ratio varied in the range $0.29-0.31$, depending on ratio of the sides of column's section.

Based on the study results of magnitude ratio of bending moment and punching force $\mathrm{M}$ / $\mathrm{N}$ under the action of a uniformly distributed load by finite element modeling, the location of loading points on test sample's plate was determined in such a way that two conditions were satisfied:

1. The $\mathrm{M} / \mathrm{N}$ ratio should be in the range of $0.25-0.35$;

2. Distribution of bending moments in the slab in both directions, as well as the vertical movements of the slab, should as closely as possible correspond to the distribution of these parameters when slab is loaded with a uniformly distributed load.

\section{Discussion}

The results of a numerical study on finite element models are used in the design of a test stand for testing strength and deformability of flat reinforced concrete slabs on test samples when punching by edge column. Previously conducted studies of equivalent schemes for the loading of test samples under the action of both concentrated forces and a uniformly distributed load [24] showed a high degree of correspondence between the results of finite element modeling and the nature of test samples deformation during testing. 
The bending moments $\mathrm{M}_{\mathrm{x}}$ and $\mathrm{M}_{\mathrm{y}}$ in punching zone of plate for test sample under the action of concentrated forces (figure 1, a) and for multi-storey building's floor under the action of a uniformly distributed load (figure 1, b) have a similar distribution pattern. In both cases, there is a concentration of forces in the areas of plate adjacent to the column corners and a reduction in effort in the middle of the column face. A similar and even more pronounced character of forces distribution is also observed in finite element models with a ratio of column's section sides 1: 2.5 and 1: 4. A similar pattern of tangential stresses distribution in slab along the column perimeter was noted by authors $[5,6]$, who on a finiteelement model performed a numerical study of the stress state of a flat plate in punching zone.

The distribution of bending moments $\mathrm{M}_{\mathrm{x}}$ and $\mathrm{M}_{\mathrm{y}}$ in longitudinal and transverse directions for plate of test samples under the action of concentrated forces and for multistorey building's floor under the action of a uniformly distributed load (figure 2) also shows a high degree of convergence for all the cases considered (ratio of the column sides 1:1, $1: 2.5$ and 1:4). This indicates a close correspondence of stress state of the test plate with the action of concentrated forces and the slab of multi-storey building under the action of a uniformly distributed load.

\section{Conclusions}

A technique for testing sample plates for punching under the action of normal forces and bending moments is developed. A feature of proposed technique is determination of the loading points on a test sample's plate by concentrated forces. The application of concentrated forces in the points found makes it possible to simulate the stress state in punching zone of a plate similar to the stressed state when a uniformly distributed load acts on the plate. In addition, it is possible to adjust the ratio of bending moment to punching force $\mathrm{M} / \mathrm{N}$ in the cross section of the column.

The earlier studies of equivalent schemes for loading test samples under the action of both concentrated forces and a uniformly distributed load [24, 25] have shown a high degree of correspondence between the results of finite element modeling and the nature of test samples deformation during testing.

\section{References}

1. J. Moe, Dev. dep. bul. D47, PCA (1961)

2. N.M. Hawkins, H.B. Falssen, R.C. Hinojosa, ACI Spec. Publ., SP-30, 127-146 (1971)

3. C.E. Broms, ACI Struct. J., 3, 292-304 (1990)

4. T. Susanto, H.K. Cheong, K.L. Kuang, J.Z. Geng, ACI Struct. J., 5, 678-687 (2004)

5. J. Sagaseta, A. Muttoni, M. Fernandez Ruiz, L. Tassinari, Mag. Conc. Res., 6, 441-457 (2011)

6. J. Sagaseta, L. Tassinari, M. Fernandez Ruiz, A. Muttoni, Eng. Struct., 77, 17-33 (2014)

7. V.B. Filatov, E.P. Bubnov, Industrial and civil engineering, 2, 86-91 (2017)

8. V.B. Filatov, MATEC Web of Conferences, 117, 00045 (2017)

9. V.I. Travush, S.G. Emel'yanov, V.I. Kolchunov, Industrial and civil engineering, 7, 20-27 (2015)

10. A.G. Tamrazyan, Industrial and civil engineering, 7, 26-27 (2012) 
11. E.N. Kodysh, N.N. Trekin, D.N. Trekin, Concrete and reinforced concrete - glance at future: III All-Russian (II International) Conference on concrete and reinforced concrete, I, 69-75 (2014)

12. V.I. Travush, V.I. Kolchunov, N.V. Klyueva, Industrial and civil engineering, 3, 4-11 (2015)

13. A.G. Tamrazyan,_Yu.N. Zvonov, Industrial and civil engineering, 7, 24-28 (2016)

14. N.N. Trekin, D.A. Pekin, Industrial and civil engineering, 7, 17-20 (2014)

15. A. Muttoni, ACI Struct. J., 4, 440-450 (2008)

16. V.B. Filatov, Bulletin of civil engineers, 5, 80-84 (2013)

17. V.B. Filatov, A.A. Suvorov, Procedia Engineering, 153, 144-150 (2016)

18. A.N. Bolgov, A.Z. Sokurov, Concrete and reinforced concrete - glance at future: III All-Russian (II International) Conference on concrete and reinforced concrete, IV, 139-149 (2014)

19. A.N. Bolgov, D.M. Yakimovich, Concrete and reinforced concrete-glance at future: III All-Russian (II International) Conference on concrete and reinforced concrete, I, 224-233 (2014)

20. J.D. Mortin, A. Ghali, ACI Struct. J., 2, 191-198 (1991)

21. E.F. El-Salakawy, M.A. Polak, M.H. Soliman, ACI Struct. J., 1, $79-87$ (1999)

22. A.G. Sherif, W.H. Dilger, ACI Struct. J., 3, 455-467 (2000)

23. E. Anggadjaja, T. Susanto, ACI Struct. J., 5, 541-551 (2008)

24. V.B. Filatov, E.P. Bubnov, MATEC Web of Conferences, 86, 01007 (2016)

25. V.B. Filatov, E3S Web of Conferences, 33, 02007 (2018) 